\section{Kidney \\ Blood Pressure Research}

\title{
The Unexpected Effects of L-Carnitine Supplementation on Lipid Metabolism in Hemodialysis Patients
}

\author{
Lea Katalinic Branimir Krtalic $^{\mathrm{b}}$ Bojan Jelakovic ${ }^{\mathrm{a}, \mathrm{b}} \quad$ Nikolina Basic-Jukic $\mathrm{C}^{\mathrm{a}, \mathrm{b}, \mathrm{c}}$ \\ aDepartment of Nephrology, Arterial hypertension, Dialysis and Transplantation, University Hospital \\ Centre Zagreb, Zagreb, bSchool of Medicine, University of Zagreb, Zagreb, 'School of Medicine, \\ University of Osijek, Osijek, Croatia
}

\section{Key Words}

L-carnitine $\cdot$ Hemodialysis $・$ Lipid status $・$ Blood pressure $・$ Supplementation $•$ Outcome

\begin{abstract}
Background/Aims: There is a growing body of evidence that the long-term hemodialysis (HD) treatment leads to disturbances of carnitine homeostasis but the results of L-carnitine supplementation in HD patients have been conflicting. In the present prospective study, we investigated the effectiveness of intravenous L-carnitine in mitigating dialysis-related proteinenergy wasting (PEW) based on pre-treatment albumin levels. Methods: Fifty patients (46\% male, mean age $63 \pm 18.28$ years, HD vintage 37.5 (7-288) months) received $1 \mathrm{~g}$ L-carnitine intravenously at the end of every HD session for 12 months. Clinical data were obtained from the medical records and charts. Intradialytic hypotension periods (defined as a decrease of systolic blood pressure by $\geq 20 \mathrm{mmHg}$ ) were recorded. Dietary habits were evaluated using a selfadministered questionnaire prior to L-carnitine supplementation. Laboratory parameters were measured prior to the supplementation and controlled in 6-months intervals. Anthropometric measurements were performed prior to HD session, including "dry" body weight and height, body mass index (BMI), and body composition analysis using bioimpedance spectroscopy. Malnutrition-inflammation score (MIS) was used as a scoring system representing the severity of PEW and an indicator of general functional capacity. Results: A significant increase in total cholesterol, predominantly on the account of LDL was found $(p=0.005)$. Simultaneously, HDL decreased $(p=0.001)$ while triglyceride levels remained unchanged. Although the rise in serum prealbumin could be observed, lean tissue index (LTI) decreased and fat tissue index (FTI) increased which resulted in reduction of the LTI/FTI ratio $(p=0.002)$. When divided into two groups according to the pre-treatment albumin values $(<35 \mathrm{~g} / \mathrm{L}$ or $\geq 35 \mathrm{~g} / \mathrm{L})$, patients from the higher albumin group showed significant increase in prealbumin $(p=0.005)$, and improved MIS $(p=0.03)$. Multivariate regression analysis showed that higher FTI after introduction of $\mathrm{L}$-carnitine led to greater hemodynamic stability (OR 1.709, 95\% CI 1.006-2.905, $p=0.048$ ). As
\end{abstract} \begin{tabular}{ll}
\hline Prof. Nikolina Basic-Jukic, & Department of Nephrology, Arterial Hypertension, Dialysis and Transplantation, University Hospital Centre \\
MD, PhD & Zagreb, School of Medicine, University of Zagreb and School of Medicine, University of Osijek,
\end{tabular} Kispaticeva 12, 10000 Zagreb (Croatia),Tel. +385-1-2367-177, E-Mail nina_basic@net.hr 


\section{Kidney Blood Pressure Research}

Kidney Blood Press Res 2018;43:1113-1120

\begin{tabular}{l|l}
\hline DOI: $10.1159 / 000491807$ & (C) 2018 The Author(s). Published by S. Karger AG, Basel
\end{tabular}

Published onlıne: 16 July, 2018

www.karger.com/kb

Katalinic et al.: Carnitine Supplementation in Hemodialysis Patients

there was no differences in HD treatment characteristics, primery kidney disease or residual diuresis we could conclude that positive energy balance (with an increase in prealbumin and FTI) eventually led to better hemodynamic stability. Conclusion: Our results show significant effects of L-carnitine supplementation on lipid metabolism. Further clinical trials, as well as experimental research are needed to define the role of lipid metabolism in CKD population. Significant benefits of L-carnitine supplementation in patients with better initial serum albumin levels suggest that this therapy should not be restricted to patients with the worst nutritional and overall status.

\section{Introduction}

Carnitine is an essential enzyme co-factor in energy metabolism, playing a vital role in $\beta$-oxidation of long-chain fatty acids [1, 2]. Given the crucial role it plays, carnitine plasma and tissue concentrations should be maintained relatively constant. Through tubular reabsorption, L-carnitine synthesis and selective short-chain carnitine esters excretion kidney is one of the key elements in preserving this balance [3]. Thus, chronic kidney disease (CKD) leads to significant disturbances of carnitine homeostasis, especially free plasma carnitine levels and carnitine muscle deposits [4]. Dialysis-related carnitine deficiency (defined as predialysis plasma concentration of free carnitine $<40 \mu \mathrm{mol} / \mathrm{L}$ ) presents as the overlapping of anemia hyporesponsive to erythropoietin (EPO) therapy, intradialytic hypotension (IDH), cardiovascular (CV) complications and skeletal muscle dysfunction [5]. However, results of L-carnitine supplementation in hemodialysis (HD) patients have been conflicting. Some reports claimed L-carnitine to have a benefitial effect on mitigating EPO hyporesponsiveness, reducing dialysis-related muscle cramping and meliorating serum lipid profile [6-8]. Other studies failed to demonstrate such effects $[9,10]$.

With its major role as a metabolic intermediate, we hypothesized that L-carnitine supplementation could improve nutritional status in HD patients. The main aim of this prospective study was to evaluate the effectiveness of intravenous L-carnitine in mitigating dialysis-related protein-energy wasting (PEW) based on pretreatment albumin levels.

\section{Materials and Methods}

The current study was performed at the dialysis unit in the University hospital centre (UHC) Zagreb. Study was approved by the UHC Zagreb Ethics commitee. Among 121 patients treated at our unit, a total of 50 patients received $1 \mathrm{~g}$ L-carnitine (Carnitene Sigma-Tau, Alfasigma Group) intravenously (5 ml of preparation applied slowly within 2-3 minutes) at the end of every HD session for 12 months. Inclusion criteria were as follows: at least 6 months of HD treatment, poor appetite with unintentional weight loss $\geq 5 \%$ over 3 months, and signs of PEW with serum albumin levels $\leq 38 \mathrm{~g} / \mathrm{L}$ and Malnutrition-Inflammation Score (MIS) $\geq 5$. Exclusion criteria were uncontrolled and untreated malignant disease, diabetes mellitus and lipid lowering therapy. Clinical data were obtained from the medical records and charts. This included demographic data, underlying kidney disease, HD vintage and treatment characteristics (duration, ultrafiltration (UF) rate, blood flow, Kt/V), EPO therapy and intravenous iron dose, blood pressure (BP) before and after dialysis session as well as residual kidney function (daily urine output $>300 \mathrm{ml}$ ). IDH periods (defined as a decrease of systolic blood pressure by $\geq 20 \mathrm{mmHg}$ ) were recorded. The following dietary habits were evaluated using a self-administered questionnaire prior to L-carnitine supplementation - number of meals per day, skipping breakfast, skipping intradialytic meal and number of meat products consumated weekly. Appetite was graded 6 and 12 months after the start of supplementation. Laboratory parameters were measured prior to the supplementation and controlled in 6-months intervals. Anthropometric measurements were performed prior to HD session, including „dry“ body weight and height, body mass index (BMI), and body composition analysis using bioimpedance spectroscopy (The Fresenius Medical Care Body Composition Monitor - BCM). MIS was used as a scoring system representing the severity of PEW and an indicator of general functional capacity [11]. 


\section{Kidney Blood Pressure Research}

\section{Statistical analysis}

Statistical analysis was performed using Stata/SE 11.2 for Windows (StataCorp LP, USA). Differences between two groups were analyzed by Pearson's $\chi^{2}$ test, (or Fisher's exact test if any expected cell frequency in contingency table was $\leq 5$ ) for categorical variables, by Student's $t$-test for normally distributed continuous variables and by Wilcoxon test for non-normally distributed continuous variables, at the level of significance $\mathrm{P}<0.05$. Spearman Rank Order Correlations was used to determine correlation between variables.

\section{Results}

There were 23 male (46\%) and 27 female (54\%) patients, mean age $63 \pm 18.28$ years. The leading cause of CKD was chronic glomerulonephritis (36\%), followed by nephroangiosclerosis (18\%) and polycystic kidney disease (PKD) (16\%). The median time spent on HD was 37.5 (7-288) months, with a minimum treatment time of 3 hours for 2 to 4 times a week, blood flow rate $290.8(250-350) \mathrm{ml} / \mathrm{min}$ and average Kt/V 1.29. Bicarbonate $\mathrm{HD}$ and ultrapure dialysate with a flow rate of $500 \mathrm{ml} / \mathrm{min}$ was used for all patients, as well as high-flux polysulphone dialysers. Symptomatic IDH occurred in $26 \%$ of patients (in $9.79 \%$ of dialysis sessons) prior to L-carnitine applications. The primary kidney disease had no influence on neither nutritional parameters nor on L-carnitine supplementation effects. Wilcoxon test revealed that L-carnitine supplementation in our cohort did not influence hemoglobin levels nor led to erythropoetin or intravenous iron dose modifications. There were 8 patients with PKD. Their hemoglobin value was $118 \mathrm{~g} / \mathrm{L}$ (range 99.8-128.5) before, and $116.5 \mathrm{~g} / \mathrm{L}$ (range 95.8-137) ( $\mathrm{p}=0.73$ ) after the treatment with L-carnitine, while patients with other primary kidney diseases had hemoglobin levels $109 \mathrm{~g} / \mathrm{L}$ (range 96-115) before, and $110 \mathrm{~g} / \mathrm{L}$ (104.5-118) after the treatment with L-carnitine, respectively ( $\mathrm{p}=0.51)$.

L-carnitine supplementation had pronounced effects on lipid metabolism during the one-year period. Serum concentrations of HDL cholesterol decreased, while LDL cholesterol levels and fat tissue index (FTI) significantly increased. Although prealbumin fraction increased lean tissue index (LTI) fell, thereby leading to decreased LTI/FTI ratio (Table 1).

Table 1. Parameters in both groups according to albumin values prior and after L-carnitine supplementation. *Wilcoxon test

\begin{tabular}{|c|c|c|c|c|c|c|}
\hline \multirow{2}{*}{ Parameter } & \multicolumn{2}{|c|}{$\begin{array}{c}\text { Serum albumin }<35 \mathrm{~g} / \mathrm{L} \\
\text { median (interquartile range) }\end{array}$} & \multirow[t]{2}{*}{$\mathrm{P}^{*}$} & \multicolumn{2}{|c|}{$\begin{array}{c}\text { Serum albumin } \geq 35 \mathrm{~g} / \mathrm{L} \\
\text { median (interquartile range) }\end{array}$} & \multirow{2}{*}{$\mathrm{P}^{*}$} \\
\hline & Prior $(\mathrm{N}=12)$ & After $(\mathrm{N}=11)$ & & Prior $(\mathrm{N}=37)$ & After $(\mathrm{N}=33)$ & \\
\hline Body weight $(\mathrm{kg})$ & $70.5(59-81.83)$ & $74(55-89)$ & 0.201 & $67(44-112)$ & $67(44-112)$ & 0.456 \\
\hline Body height $(\mathrm{cm})$ & $171(159-181)$ & $168(164-181)$ & 0.500 & $167(153-160)$ & $168(153-179)$ & 0.366 \\
\hline BMI $\left(\mathrm{kg} / \mathrm{m}^{2}\right)$ & $24.5(20.68-30)$ & $26.1(21.86-33.09)$ & 0.513 & $24.35(17.1-35)$ & $24.84(16.85-33.81)$ & 0.931 \\
\hline Cholesterol (mmol/L) & $3.65(3.15-4.68)$ & $3.4(2.8-5.1)$ & 0.648 & $4(2.2-7.8)$ & $4.1(2.6-8.4)$ & 0.049 \\
\hline Triglycerides $(\mathrm{mmol} / \mathrm{L})$ & $0.89(0.08-5.13)$ & $1.12(0.1-3.05)$ & 0.112 & $1.25(0.52-35.13)$ & $1.47(0.29-26.14)$ & 0.226 \\
\hline $\mathrm{HDL}(\mathrm{mmol} / \mathrm{L})$ & $1.17(0.22-1.88)$ & $1.08(0.67-2.08)$ & 0.495 & $1.07(0.68-2.13)$ & $0.92(0.6-1.9)$ & 0.002 \\
\hline $\mathrm{LDL}(\mathrm{mmol} / \mathrm{L})$ & $1.79(0.89-3.65)$ & $1.87(0.44-3.56)$ & 0.280 & $2.32(0.81-5.14)$ & $2.54(1.65-5.38)$ & 0.007 \\
\hline Hemoglobin $(\mathrm{g} / \mathrm{L}$ ) & $109(92.5-118.25)$ & 113 (104-119) & 0.158 & $111(85-150)$ & $108(91-147)$ & 0.627 \\
\hline Ferritin $(\mu \mathrm{g} / \mathrm{L})$ & $190.25(19.9-833.1)$ & $210.6(67.7-1025)$ & 0.009 & 359 (37.5-1141) & $412.1(35.2-1034)$ & 0.133 \\
\hline Iron $(\mu \mathrm{mol} / \mathrm{L})$ & $14.5(7-25)$ & $10(3-18)$ & 0.139 & $11(5-33)$ & $14(5-27)$ & 0.329 \\
\hline EPO dose (IU/month) & $32000(8000-48000)$ & $48000(16000-48000)$ & 0.99 & $32000(0-72000)$ & $24000(0-64000)$ & 0.596 \\
\hline IV Fe dose (mg/month) & $125(0-250)$ & $125(0-250)$ & 0.102 & $125(0-400)$ & $122(0-250)$ & 0.027 \\
\hline Potassium (mmol/L) & $4.3(3.5-5.7)$ & $4.9(3.8-6.2)$ & 0.055 & $5.1(4.3-7.2)$ & $5.3(3.8-6.4)$ & 0.637 \\
\hline Calcium (mmol/L) & $2.33(2.17-2.52)$ & $2.28(2.02-2.48)$ & 0.198 & $2.24(1.95-2.71)$ & $2.26(1.9-2.7)$ & 0.467 \\
\hline Phosphorus (mmol/L) & $1.41(0.72-2.13)$ & $1.33(0.36-2.25)$ & 0.363 & $1.68(0.74-3.07)$ & $1.82(0.87-3.32)$ & 0.047 \\
\hline Total protein $(\mathrm{g} / \mathrm{L})$ & $63(51-69)$ & $60(45-75)$ & 0.875 & $66(56-77)$ & $67(60-75)$ & 0.105 \\
\hline Serum albumin $(\mathrm{g} / \mathrm{L})$ & $34.25(31-35)$ & $33.2(26.1-34.8)$ & 0.280 & $37.6(35.2-44.2)$ & $38.7(35.3-44.3)$ & 0.338 \\
\hline MIS & $11.5(6-16)$ & $11(8-18)$ & 0.899 & $8(5-13)$ & $6(2-15)$ & 0.030 \\
\hline Prealbumin (g/L) & $0.45(0.3-0.7)$ & $0.5(0.4-1.7)$ & 0.055 & $0.6(0.4-0.8)$ & $0.7(0.4-0.9)$ & 0.005 \\
\hline Overhydration (L) & $2.05(-0.7-6.8)$ & $2.1(0.1-5.1)$ & 0.753 & $2.2(-2.1-6.8)$ & $2.1(-9-5.2)$ & 0.532 \\
\hline LTI $\left(\mathrm{kg} / \mathrm{m}^{2}\right)$ & $11.1(6.6-15.6)$ & $9.5(5.8-14.4)$ & 0.140 & $12.9(8.8-21.1)$ & $11.25(6.4-15.3)$ & 0.004 \\
\hline FTI $\left(\mathrm{kg} / \mathrm{m}^{2}\right)$ & $12.15(0.5-24)$ & $16.3(2.7-26.2)$ & 0.293 & $10.65(4.7-23.3)$ & $13(4.1-21.4)$ & 0.001 \\
\hline LTI/FTI ratio & $0.93(0.29-28.6)$ & $0.55(0.22-4.52)$ & 0.088 & $1.27(0.38-3.26)$ & $0.98(0.34-3.32)$ & 0.005 \\
\hline
\end{tabular}




\section{Kidney \\ Blood Pressure Research}

When divided into two groups according to the pre-treatment albumin values $(<35 \mathrm{~g} / \mathrm{L}$ or $\geq 35 \mathrm{~g} / \mathrm{L})$, patients in the low albumin group increased prealbumin from 0.45 to $0.5 \mathrm{~g} / \mathrm{L}$ $(p=0.055)$ and slightly decreased MIS from 11.5 to 11 ( $\mathrm{p}=0.899$ ) (Fig. 1, A and B). However, patients from the higher albumin group showed significant increase in prealbumin from 0.6 to $0.7 \mathrm{~g} / \mathrm{L}$ $(\mathrm{p}=0.005)$, and improved MIS from 8 to 6 ( $p=0.03$, Fig. 2, A and B). These patients also showed significant improvement in appetite and better functional capacity (Fisher's exact test, $\mathrm{p}=0.021$ ). The same effects of L-carnitine supplementation were also clearly present after analyzing the patients according to their primary kidney disease (PKD vs. other primary kidney disease, Table 2). Groups did not differ regarding the number of dialysis sessions per week (average 2.92 vs. 2.89, $\mathrm{p}=0.56$ ), dialysis vintage (median 103.5 (12-110) vs. 98 (7-288) months, $\mathrm{p}=0.64)$, $\mathrm{Kt} / \mathrm{V}$ (mean $1.2 \pm 0.33$ vs. $1.31 \pm 0.22$, $\mathrm{p}=0.62$ ) or residual diuresis (median 750 (0-2000) vs $560(0-2000) \mathrm{ml}, \mathrm{p}=0.35)$ for the albumin $<35 \mathrm{~g} / \mathrm{L}$ or $\geq 35 \mathrm{~g} / \mathrm{L}$ group, respectively. There was also no differences in dietary habits among the groups.

Before the introduction of L-carnitine, with the increase of BMI, FTI also increased (Rho=0.758, p<0.001), with a reduction of LTI/FTI ratio (Spearman Rho $=-0.571, \mathrm{p}<0.001$, Fig. 3, A and B). After the introduction of L-carnitine, these correlations were more pronounced (Rho 0.770 and -0.582 , respectively, $\mathrm{p}<0.001$ ). Multivariate regression analysis showed that higher FTI after introduction of L-carnitine led to greater hemodynamic stability with number of IDH episodes

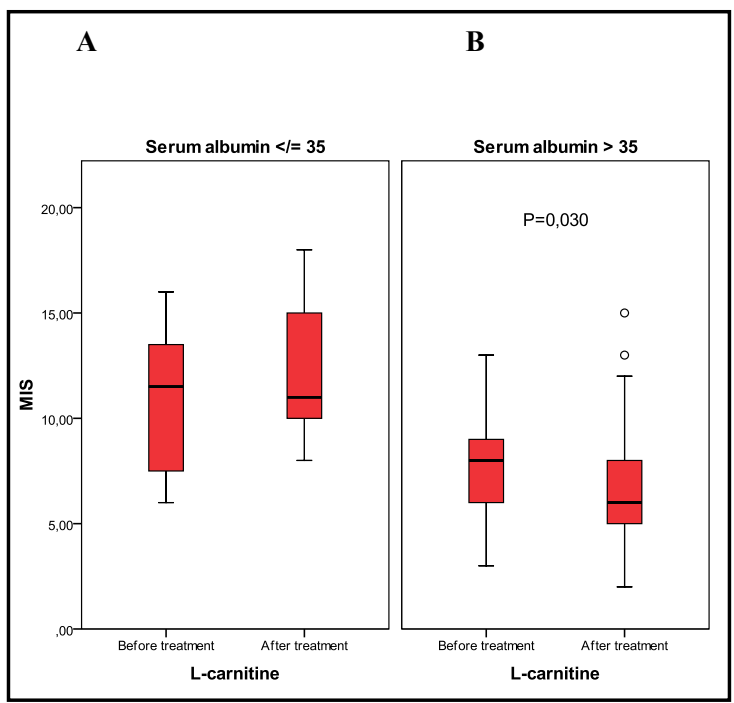

Fig. 1. Changes in Malnutrition-Inflammation Score after L-carnitine supplementation according to pretreatment albumin values.

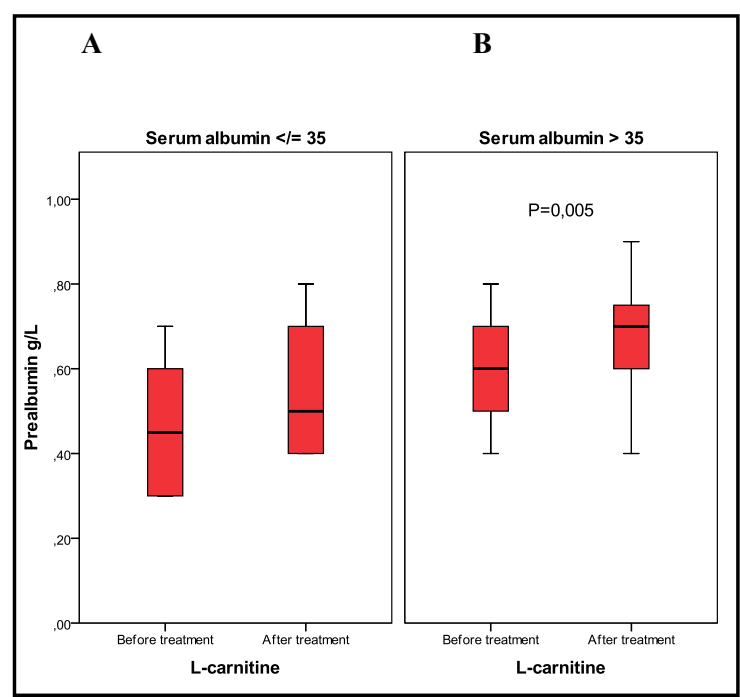

Fig. 2. Changes in prealbumin after L-carnitine supplementation according to pretreatment albumin values. significantly decreasing during the 12-months period (OR 1.709, 95\% CI 1.006-2.905, p=0.048), and appearing in only $8 \%$ of patients (in 5.48\% of dialysis sessions; Fisher's exact test, p=0.049, Table 3).

$\mathrm{L}$-carnitine treatment had no negative repercussions on dialysis adequacy (average $\mathrm{Kt} / \mathrm{V}$ was 1.29 before and 1.32 after the treatment with L-carnitine, Fisher's exact test $p=0.24$ ), nor were there any adverse events of the treatment. 


\section{Kidney Blood Pressure Research}

Table 2. Parameters in groups according to primary kidney disease prior and after L-carnitine supplementation. *Wilcoxon test

\begin{tabular}{|c|c|c|c|c|c|c|}
\hline \multirow{2}{*}{ Parameter } & \multicolumn{2}{|c|}{$\begin{array}{l}\text { Polycystic kidney disease }(\mathrm{n}=8) \\
\text { median (interquartile range) }\end{array}$} & \multirow{2}{*}{$\mathrm{P}^{*}$} & \multicolumn{2}{|c|}{$\begin{array}{l}\text { Other primary diseases ( } \mathrm{n}=42 \text { ) } \\
\text { median (interquartile range) }\end{array}$} & \multirow{2}{*}{$\mathrm{P}^{*}$} \\
\hline & Prior & After & & Prior & After & \\
\hline Body weight (kg) & $59.2(53-69.6)$ & $62.5(54.1-67.3)$ & 0.6 & $69.7(57-81.5)$ & $70(54.5-84)$ & 0.46 \\
\hline Body height $(\mathrm{cm})$ & $160(160-170)$ & $170(160-159.8)$ & 0.14 & $170(160-180)$ & $170(160-170)$ & 0.12 \\
\hline BMI $\left(\mathrm{kg} / \mathrm{m}^{2}\right)$ & $22.8(21.3-26.3)$ & $26.1(21.86-33.09)$ & 0.513 & $24.8(17.1-35)$ & $24.9(20.6-28.8)$ & 0.35 \\
\hline Cholesterol (mmol/L) & $4.2(3.6-5.3)$ & $4.7(3.6-5.4)$ & 0.36 & $3.9(3.25-4.7)$ & $4.1(3.4-5.1)$ & 0.17 \\
\hline Triglycerides (mmol/L) & $1.1(0.9-1.5)$ & $1.7(1.2-2.2)$ & 0.02 & $1.25(0.52-35.13)$ & $1.47(0.29-26.14)$ & 0.04 \\
\hline HDL (mmol/L) & $1.3(1.1-1.3)$ & $1.1(0.8-1.2)$ & 0.02 & $1.1(0.9-1.3)$ & $1.0(0.8-1.3)$ & 0.02 \\
\hline $\mathrm{LDL}(\mathrm{mmol} / \mathrm{L})$ & $2.5(1.8-3.3)$ & $2.7(2-3.4)$ & 0.4 & $2.0(1.6-2.9)$ & $2.3(1.9-3.1)$ & 0.008 \\
\hline Hemoglobin (g/L) & $118(99.8-128.5)$ & $116.5(95.8-137)$ & 0.73 & $109(96-115)$ & $110(104.5-118)$ & 0.51 \\
\hline Iron $(\mu \mathrm{mol} / \mathrm{L})$ & $9.5(8-11.8)$ & $14(10.5-17.3)$ & 0.5 & $11(8-16)$ & $11(8.5-16)$ & 0.37 \\
\hline EPO dose (IU/month) & $20000(6000-24000)$ & $24000(0-36000)$ & 0.66 & $32000(0-72000)$ & $24000(0-64000)$ & 0.596 \\
\hline IV Fe dose (mg/month) & $187.5(32.8-250)$ & $125(0-250)$ & 0.18 & $125(93.8-250)$ & $125(31.3-162.5)$ & 0.14 \\
\hline Total protein (g/L) & $66(63.3-72.3)$ & $67.5(64.3-73.5)$ & $>0.99$ & $65(62-68)$ & $66(62-68.75)$ & 0.18 \\
\hline Serum albumin (g/L) & $37.1(36.1-39.9)$ & $37.1(35.4-41.2)$ & 0.46 & $37(34.9-39)$ & $37.6(34.5-40.2)$ & 0.94 \\
\hline MIS & $7.5(6-8.8)$ & $6(5-9.5)$ & 0.010 & $9(6.8-11)$ & $8(6-10.3)$ & 0.049 \\
\hline Prealbumin (g/L) & $0.6(0.6-0.7)$ & $0.7(0.5-0.8)$ & 0.02 & $0.6(0.5-0.7)$ & $0.7(0.5-0.7)$ & 0.003 \\
\hline Overhydration (L) & $1.8(0.1-4.8)$ & $1.6(0-3.1)$ & 0.14 & $2(0.9-3.7)$ & $2.3(0.9-4)$ & 0.67 \\
\hline LTI $\left(\mathrm{kg} / \mathrm{m}^{2}\right)$ & $11.6(10.6-14)$ & $9.4(7.2-11.9)$ & 0.01 & $12.5(10.1-13.9)$ & $11.2(9.9-12.9)$ & 0.04 \\
\hline FTI $\left(\mathrm{kg} / \mathrm{m}^{2}\right)$ & $10.4(8-13.1)$ & $14.8(10-18)$ & 0.02 & $10.8(7.7-15.2)$ & $13(8.1-16.9)$ & 0.03 \\
\hline LTI/FTI ratio & $1.3(0.9-1.5)$ & $0.8(0.4-1)$ & 0.01 & $1.2(0.8-1.8)$ & $0.9(0.6-1.5)$ & 0.02 \\
\hline
\end{tabular}

Fig. 3. Changes in LTI/FTI ratio after L-carnitine supplementation according to pretreatment albumin values.
A

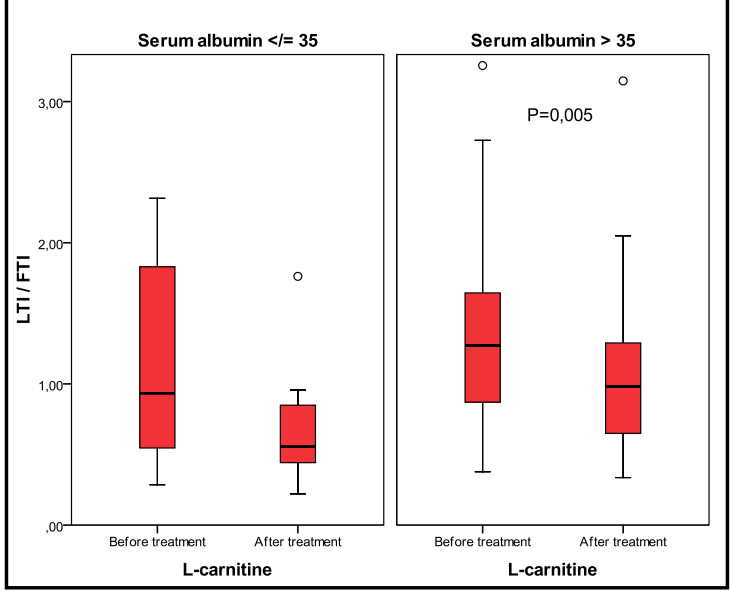

Table 3. Distibution of patients with and without hypotension prior and after L-carnitine supplementation.

* Fisher's exact test

\begin{tabular}{|c|c|c|c|c|c|}
\hline \multirow{2}{*}{ Parameter } & & \multicolumn{3}{|c|}{ Number (\%) of patients prior to L-carnitine supplementation } & \multirow{2}{*}{$\mathrm{P}^{*}$} \\
\hline & & Without hypotension & With hypotension & Total & \\
\hline \multirow{3}{*}{ After L-carnitine supplementation } & Without hypotension & $36(97)$ & $10(77)$ & $46(92)$ & \multirow{3}{*}{0.049} \\
\hline & With hypotension & $1(3)$ & $3(23)$ & $4(8)$ & \\
\hline & Total & $37(100)$ & $13(100)$ & $50(100)$ & \\
\hline
\end{tabular}

\section{Discussion}

Our results demonstrated marked effects of intravenous L-carnitine supplementation on lipid metabolism. A significant increase in total cholesterol, predominantly on the account of LDL was found. Simultaneously, HDL decreased while triglyceride levels remained unchanged. Although the rise in serum prealbumin could be observed, LTI decreased and FTI increased which resulted in reduction of the LTI/FTI ratio. Alhough at first these changes appear as negative, they were associated with improved hemodynamic stability, MIS and appetite, and were more pronounced in patients with better initial albumin levels. 


\section{Kidney Blood Pressure Research}

Our study showed that 12 months of intravenous L-carnitine supplementation had no impact on hemoglobin levels nor did it lead to a reduction in EPO requirement. This finding is in accordance with Handelman's study from 2006 which showed that 6 months of L-carnitine administration to patients in a large dialysis unit did not change hemoglobin or EPO dose [12]. Meta-analysis by Hurot et al. suggested a beneficial effect of L-carnitine supplement on anaemia control in HD patients with reducing the EPO resistance index and improving EPO efficiency as compared with control groups. They were not able to find doseresponse pattern, and did not observe a time gap for this effect [13]. Due to small number of studies and limited number of patients Chen et al. recently conducted another meta-analysis which failed to confirm those findings [8].

According to our results, L-carnitine supplementation significantly decreased number of IDH episodes (OR 1.709, 95\% CI 1.006-2.905, p=0.048), complicating only $5.48 \%$ of dialysis sessions; Fisher's exact test, $\mathrm{p}=0.049$ ). IDH is a common complication of HD which could lead to premature treatment discontinuation, chronic underdialysis and higher mortality. It is mainly linked to poor compensatory response to ultrafiltration, with autonomic or baroreceptor failure or disturbed cardiac function leading to excessive venous pooling and abnormal vasodilation [14]. New evidence also suggests that mitochondria dysfunction might have a primary role in the development of CKD related complications. This results in mitochondria-derived oxidative stress and leads to persistent tissue damage. As L-carnitine is an essential enzyme co-factor in energy metabolism it could be one of the so called mitochondria-targeted molecules which could modulate the specific signal transduction cascade and lead to significant improvement of cellular defense against chronic inflammation and oxidative stress [15]. Moreover, after performing multivariate regression analysis we were able to show a link between the FTI increase and a lesser number of IDH episodes which could suggest that positive energy balance (with an increase in prealbumin and FTI) and a reduction of MIS eventually led to better hemodynamic stability.

The relationship between L-carnitine therapy and lipid metabolism has been widely investigated but with conflicting results. Our data are in contrast with previously published studies which described either beneficial effects or no changes at all. By beneficial effects authors have stressed a significant decline in triglycerides, free fatty acids and cholesterol levels (total and LDL fraction) and an increase in HDL [16-19]. On the other hand, results obtained by two systematic reviews and meta-analysis provided no evidence that L-carnitine could impact lipid metabolism [13,20]. These differences could possibly be explained by the dose-dependent effects of carnitine proposed by some reports $[8,21]$.

Cardiovascular (CV) complications are the leading cause of mortality in HD patients, with accelerated atherosclerosis and PEW being among the most important risk factors leading to poor outcome [22]. Although obesity, hypercholesterolemia and higher BP values are wellestablished risk factors for $\mathrm{CV}$ disease and poor outcome in general population, it seems that higher rather than lower values for these risk factors act protective in CKD patients [2326]. This phenomenon is called „reverse epidemiology“ or „dialysis-risk-paradox" [23, 26, 27]. Several possible mechanisms explaining favorable effect of higher BMI on survival have been proposed so far. All hypothetical explantations lead to one particular point - adipose tissue does not serve only as lipid storage but is also a highly active endocrine organ [28, 29]. As PEW is defined not only by the continuous decline in protein but also fat reserves, its treatment represents a challenge and should be focused on maintaining the energy pool as whole.

Even though our results are contradictory to previously published studies [13, 16-20], one could speculate whether this slight but significant increase in total and LDL cholesterol and FTI could in fact be protective in HD patients. Although at first these changes could be claimed as undesirable they led to significant amelioration of MIS and were linked to much better appetite. Furthermore, FTI increase led to lesser number of IDH episodes. As there was no differences in HD treatment characteristics, primery kidney disease or residual diuresis we could conclude that positive energy balance (with an increase in prealbumin 


\section{Kidney Blood Pressure Research}

and FTI) eventually led to better hemodynamic stability. This hypothesis deserves further investigations. Although L-carnitine treatment had no negative repercussions on $\mathrm{Kt} / \mathrm{V}$ indeces, dialysis adequacy parameters should be carefully monitored.

Our study has some limitations including the small sample size, lack of control group, limited laboratory lipid-metabolism evaluation and short follow-up. When evaluating dietary habits by using a self-administered questionnaire prior to L-carnitine supplementation there was no differences between these two groups. However, more detailed food intake analysis was not performed. Thus, there is a possibility that the former group did not have the same dietary habits as the other analyzed group. Although this may be the potential source of a bias, patients from the higher albumin group clearly stated improvements in appetite and functional capacity that in our oppinion led to better serum prealbumin and a decrease in MIS. This was also mirrored through the changes in serum lipid profile and phosporus levels.

Additionally, comparing both pre- and postdialysis body composition measurements as well as more detailed food intake analysis might be useful in further studies. Further clinical trials, as well as experimental research are needed to define the role of lipid metabolism in CKD population.

\section{Conclusion}

The results of our study showed significant effects of L-carnitine supplementation on lipid metabolism. Significance of increase in the FTI remains unclear, although it may be the consequence of increase in the "healthy" and protective fat tissue. Due to significant benefits of L-carnitine supplementation in patients with better initial serum albumin levels, this therapy should not be restricted to patients with the worst nutritional and overall status.

\section{Acknowledgements}

All authors have contributed significantly according to the definition set up by the ICMJE.

There have been no involvments that might raise the question of bias in the work reported or in the conclusions, implications, or opinions stated.

\section{Disclosure Statement}

The authors declare no conflicts of interest regarding the publication of this paper.

\section{References}

1 Lynch KE, Feldman HI, Berlin JA, Flory J, Rowman CG, Brunelli SM: Effects of L-carnitine on dialysis-related hypotension and muscle cramps: a meta-analysis. Am J Kidney Dis 2008;52:962-971.

$\checkmark 2$ Indiveri C, Iacobazzi V, Tonazzi A, Giangregorio N, Infantino V, Convertini P, Console L, Palmieri F: The mitochondrial carnitine / acylcarnitine carrier: function, structure and physiopathology. Mol Aspects Med 2011;32:223-233.

3 Evans AM: Dialysis-related carnitine disorder and levocarnitine pharmacology. Am J Kidney Dis 2003;41:13-26.

4 Reuter SE, Faull RJ, Evans AM: L-carnitine supplementation in the dialysis population: are Australian patients missing out? Nephrology (Carlton) 2008;13:3-16.

5 Eknoyan G, Latos D, Lindberg J, National Kidney Foundation Carnitine Consensus Conference: Practice recommendations for the use of L-carnitine in dialysis-related carnitine disorder. National Kidney Foundation Carnitine Consensus Conference. Am J Kidney Dis 2003;41:868-876. 


\section{Kidney \\ Blood Pressure Research}

-6 Bellinghieri G, Savica V, Mallamace A, Di Stefano C, Consolo F, Spagnoli LG, Villaschi S, Palmieri G, Corsi M, Maccari F: Correlation between increased serum and tissue L-carnitine levels and improved muscle symptoms in hemodialysed patients. Am J Clin Nutr 1983;38:523-531.

7 Kletzmayr J, Mayer G, Legenstein E, Heinz-Peer G, Leitha T, Hörl WH, Kovarik J: Anemia and carnitine supplementation in hemodialysed patients. Kidney Int Suppl 1999;69:S93-106.

8 Chen Y, Abbate M, Tang L, Cai G, Gong Z, Wei R, Zhou J, Chen X: L-carnitine supplementation for adults with end-stage kidney disease requiring maintenance hemodialysis: a systematic review and meta-analysis. Am J Clin Nutr 2014;99:408-422.

-9 Lilien MR, Duran M, Quak JM, Frankhuisen JJ, Schröder CH: Oral L-carnitine does not decrease erythropoietin requirement in pediatric dialysis. Pediatr Nephrol 2000;15:17-20.

10 Chazot C, Blanc C, Hurot JM, Charra B, Jean G, Laurent G: Nutritional effects of carnitine supplementation in hemodialysis patients. Clin Nephrol 2003;59:24-30.

-11 Kalantar-Zadeh K, Kopple JD, Block G, Humphreys MH: A malnutrition-inflammation score is correlated with morbidity and mortality in maintenance hemodialysis patients. Am J Kidney Dis 2001;38:1251-1263.

12 Handelman GJ: Carnitine supplements have not been demonstrated as effective in patients on long-term dialysis therapy. Blood Purif 2006;24:140-142.

13 Hurot JM, Cucherat M, Haugh M, Foque D: Effects of L-canitine supplementation in maintenance hemodialysis patients: a systematic review. J Am Soc Nephrol 2002;13:708-714.

14 Selby NM, McIntyre CW: The acute cardiac effects of dialysis. Semin Dial 2007;20:220-228.

15 Granata S, Dalla Gassa A, Tomei P, Lupo A, Zaza G: Mitochondria: a new therapeutic target in chronic kidney disease. Nutr Metab 2015;12:49.

16 Chandran M, Phillips SA, Ciaraldi T, Henry RR: Adiponectin: more than just another fat cell hormone? Diabetes Care 2003;26:2442-2450.

17 Vacha GM, Giorcelli G, Siliprandi N, Corsi M: Favorable effects of L-carnitine treatment on hypertriglyceridemia in hemodialysis patients: decisive role of low levels of high-density lipoproteincholesterol. Am J Clin Nutr 1983;38:532-540.

18 Debska-Slizień, Kawecka A, Wojnarowski K, Prajs J, Malgorzewicz S, Kunicka D, Zdrojewski Z, WalysiakSzydłowska, Lipiński J, Rutkowski B: Correlation between plasma carnitine, muscle carnitine and glycogen levels in maintenance hemodialysis patients. Int J Artif Organs 2000;23:90-96.

19 Veselá E, Racek J, Trefil L, Jankovy'ch V, Pojer M: Effect of L-carnitine supplementation in hemodialysis patients. Nephron 2001;88:218-223.

20 Naini AE, Sadeghi M, Mortazavi M, Moghadasi M, Harandi AA: Oral carnitine supplementation for dyslipidemia in chronic hemodialysis patients. Saudi J Kidney Dis Transpl 2012;23:484-498.

21 Wanner C, Wieland H, Wackerle B, Boeckle H, Schollmeyer P, Horl WH: Ketogenic and antiketogenic effects of L-carnitine in hemodialysis patients. Kidney Int Suppl 1989;27:S264-268.

-22 Kalantar-Zadeh K, Rodriguez RA, Humphreys MH. Association between serum ferritin and measures of inflammation, nutrition and iron in haemodialysis patients. Nephrol Dial Transplant 2004;19:141-149.

-23 Kalantar-Zadeh K, Block G, Humphreys MH, Kopple JD: Reverse epidemiology of cardiovascular risk factors in maintenance dialysis patients. Kidney Int 2003;63:793-808.

-24 Salahudeen AK: Obesity and survival on dialysis. Am J Kidney Dis 2003;41:925-932.

25 Zager PG, Nikolic J, Brown RH, Campbell MA, Hunt WC, Peterson D, Van Stone J, Levey A, Meyer KB, Klag MJ, Johnson HK, Clark E, Sadler JH, Teredesai P: „U“ curve association of blood pressure and mortality in hemodialysis patients. Kidney Int 1998;54:561-569.

26 Nishizawa Y, Shoji T, Ishimura E, Inaba M, Morii H: Paradox of risk factors for cardiovascular mortality in uremia: is a higher cholesterol level better for atherosclerosis in uremia? Am J Kidney Dis 2001;38:S4-7.

27 Fleischmann EH, Bower JD, Salahudeen AK: Risk factor paradox in hemodialysis: better nutrition as a partial explanation. ASAIO J 2001;47:74-81.

28 Kalantar-Zadeh K, Abbott KC, Salahudeen AK, Kilpatrick RD, Horwich TB: Survival advantages of obesity in dialysis patients. Am J Clin Nutr 2005;81:543-554.

29 Stefan N, Artunc F, Heyne N, Machann J, Schleicher ED, Häring HU: Obesity and renal disease: not all fat is created equal and not all obesity is harmful to the kidneys. Nephrol Dial Transplant 2016;31:726-730. 